\title{
THE STRUCTURE OF ADULT EDUCATION AND THE PERFORMANCE OF THE LECTURE*
}

\author{
by \\ Gidada Tahir \\ Department of Extension Services, \\ University of Sokoto, Nigeria.
}

\begin{abstract}
This paper discusses the structure of Adult Education programmes and, on the basis of experiential and intuitive considerations, attempts to construct a schema of relationships between the lecture, the didactic presentation of materials, and the former. Consequently, a research agenda has been proposed. The paper concludes that the lecture is not an appropriate and effective instructional method in adult education. However, in certain circumstances, particularly with University Extension Programmes, the lecture may be an effective and expedient approach for conveying information to adults if it is properly used. Finally, adult education training agencies are called upon to intensify the use of group approaches and activity-teaching methods and techniques in their training programmes.
\end{abstract}

\section{Introduction}

It is a truism that the success of any adult education programme is dependent upon the degree to which the learner is made the focal point of the process (Knowles, 1970:88). However, a casual observation of teaching-learning process in adult education in Nigeria, tends to reveal that instructors heavily rely on the teacher-centred approaches to the neglect of the group approaches. Reasons for this tendency are not far fetched, when one realizes that instructors in adult education are a by-product of the school system, whose exposure to adult education during their formal training is very minimal, (J.C.C.: 1982:5). Therefore, when they are finally engaged in one form of adult education enterprise or another, they bring along with them such an erroneous belief that the teaching here is the same as in the formal system. Thus, implying at least in part, that instructors trained for and accustomed to teaching children are good enough to engage in the business of teaching adults. Despite the skepticism, and perhaps, actual hostility with which many adult educators regard the teachercentred approaches, the lecture is still identified as the one learning method

"Part of this paper was originally presented as "Performance structure, and Problems of lecture method in Adult Education", during a Workshop on Activity Teaching Method joinly organized by A.B.U., Zaria and the University of Lagos, on 8-5-1982, at Zaria. 
most preferred and most used in adult education (Darkenwald and Merriam, 1982:201).

The aim of this paper is to discuss the structure of adult education programmes, and the performance of the lecture as an instructional method, within the context of adult education. In other words, the notion of adult education programmes will be explicated with the view to identifying effectivenessappropriateness relationships between it and the lecture. It is not so much a matter of import as to whether the lecture is treated, vis-a-vis adult education programmes, as a conceptual construct, or as an independent variable. What is critical at this juncture, is how successful the lecture method performs in delivering certain learning experiences within the context of certain adult education activity-programmes.

The Notions of Adult Education Programme and the Lecture as a Framework for Analysis

It is important to note that a programme differs somewhat from the traditional notion of a curriculum, although certainly related to it. A sampling of definitions provided by London (1960:15), Thomas (1964:40), Axford (1970:63), and Boyle and Jahns (1970:51), reveals that the notion of an adult education programme connotes short-term learning experiences that are responsive to learner needs and are implemented outside the traditional delivery system. Additionally, this notion emphasises the characteristics of flexibility, variability, and all-inclusiveness of an adult education programme (Knox, 1980:83). However, it should not be concluded that programmes are always non-formal, highly flexible, variable, or all inclusive. Rather, and in order to ayoid confusion, there is the need to conceptualize adult education programmes as that varying along several continua, i.e. from very informal to highly structured; from very general to highly specialized; and from specific programmes to programmes that consist of a number of offerings.

Tahir (1982:8) developed a conceptual model for adult education programming, which hinges on the premise that adult education has a distinct domain, within which exists three overlapping programming modules. However, two of the modules slightly assume informal and formal structures, which are theoretically outside, but could be analytically within the traditional domain of adult education.

At the more structured end of the continuum, programme characteristics approximate traditional curriculum characteristics in several significant ways, Thus activity-programmes in this module might include inter-alia, extra-mural classes, independent study, University Extension programmes, etc. At the other 
extreme of the continuum, such activity programmes, whose characteristics may resemble informal education, predominate, for example: community development, community health, cooperative and agricultural extensions, nutrition and environmental education. These activity-programmes may or may not have direct educational objectives, although they may have implications for adult education programming. The middle section of the continuum includes such activity programmes as basic and functional literacy, trade and vocational training. This module is generally regarded in Nigeria, albeit mistakenly, as what constitutes adult education. This is more a product of governmental emphasis than what adult education actually is. Such conceptual muddle is expected since various governments in Nigeria expected adult education, as a matter of policy, to achieve two fundamental objectives: (a) provision of basic literacy and numeracy for socio-political and cultural integration, and (b) provision of teaching vocational skills for self-reliance and economic development.

Below is a schematic representation of the conceptual framework of adult education programme.

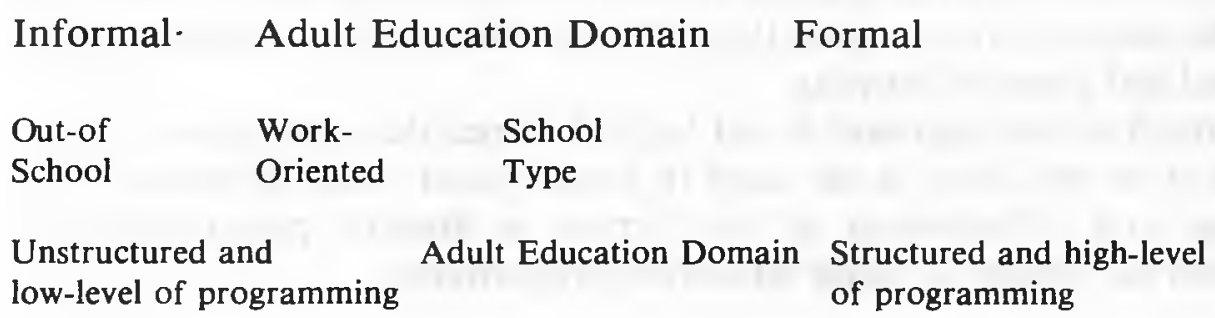

Fig. 1: A conceptual Framework of Adult Education Domain and level of programming in each module.

Generally speaking, then, it can be said that since adult education programmes are of short duration, and are strictly designed to meet the needs of the learners and not very much of the institution, it is only logical to expect that they should be flexible and variable. Futhermore, programme content could range from a fix and rigid curriculum as in the school year, or a highly flexible one, but geared to the unique needs of the individual learner. Adult education programmers may thus focus their attention on either the individual learner (I), small (S), or large (L) groups, in programme design, depending on the nature of the programme itself as well as the needs of the clients etc.

With this conception as a point of departure, a further classification of adult education programmes, in an orthodox fashion, is possible, namely, basic adult education and continuing education. Basic adult education can be likened to the beginning level of the modern primary school, in which learners are 
taught basic skills and knowledge in the areas of reading, writing, arithmetic and perhaps social studies in a broadest sense of the term. And other adult education activity-programme beyond this level can thus be regarded as continuing education, irrespective of whether it is in the forms of skill, vocational or intellectual; and remedial, or public relations. In any event, different instructional methods may be employed in different adult education activityprogrammes depending upon: (a) client's needs and motivational levels, (b) duration of the programme and (c) objective of programme. For instance, in teaching any of the components of the 3Rs, certain instructional methods will be more effective than others.

At the perspective of the lecture, it is quite apparent that few studies have been conducted in either its use in adult education situations, or its appropriateness for learning tasks other than acquisition of knowledge (Oddi, 1983:225). Furthermore, an emerging trend in the research seems to be that investigators, in the last one decade and a half, have tended to blur distinctions between lecture, discussion, and demonstration. They tended, rather to collectively deal with these techniques under the rubric "traditional approaches" and to focus their attention on studying the difference between such traditional approaches and self directed learning.

This distinction and approach is not helpful, hence the significance of this paper. That is to say, there is the need to identify and relate situational appropriateness and effectiveness of the lecture as didactic presentation of materials, and the variety of adult education programmes.

\section{Procedure}

A diagrammatic relationship between adult education activity programme (AP) and the various classes of participants (CP) on the one hand, and the degree to which the lecture is perceived to be appropriate and effective (AEs) on the other hand, has been developed. The degree of appropriatenesseffectiveness of the lecture is based on the extent to which the lecture method satisfies instrumentai criteria of acquisition of skills, knowledge and attitude on a scale of one (1) to five (5). Namely, one is equated to very appropriate and effective, two as appropriate and effective; three as moderately appropriate and effective; four as not appropriate and effective; and five as not applicable.

Participants in this study comprised of 27 adult educators from the states and Universities in Nigeria, who under went the one-week activity teaching methods in adult education which was jointly organized by the University of Lagos and A.B.U., Zaria, in May, 1982. Participants were requested to score the appropriateness of the lecture method in a given instructional situation us- 
ing the degree of appropriateness and effectiveness of the lecture method scale mentioned above. On this basis, percentages within and across individual situational cases, classes and categories were computed to determine the extent of appropriateness and effectiveness of the lecture for comparative analysis. This paper does not pretend that the selected activity-programme are exhaustive of the domain of adult education. Nonetheless, for all intends and purposes, they have adequately portrayed the reality of adult education.

\section{Results}

Data on the relationships between adult education activity-programme, class of participants and appropriateness-effectiveness of the lecture as instructional method are presented in Appendix I.

The nine major categories and twenty-seven sub-categories are only few possible examplars of appropriateness-effectiveness relationships between selected adult education programmes and the lecture method as an instructional medium. On the basis of the data presented in the schema, some general statements about the relationships can be made.

It is quite clear that the performance of the lecture is variable. But on the whole, it is below expectation as an instructional method in most adult education activity-programmes under consideration.

In such adult education activities as public lecture, community development and seminars and conferences, the performance of the lecture is moderately appropriate and effective $(60 \% \pm)$. Individually, each programme has the following appropriateness effectiveness score: public lecture, $56 \%$. Community development, $61 \%$, and Seminars and Conferences, 67\%. Furthermore, the data indicate that the lecture is not appropriate and effective $(80 \% \pm)$ as an instructional method in basic and functional literacy programes, and correspondence education. A score of $80 \%$ has been recorded in both categories. Of all the nine selected adult education programmes, vocational training, with a score of $100 \%$, is the one activity - programme category in which the lecture is totally inapplicable. However, it should not be mistaken that this category is completely devoid of elements of the lecture. Even in the teaching of typewriting, mechanics or sewing, a minimum application of some forms of lecture, viz, introduction, summary and conclusion, are expected.

Individual differences within classes are also discernible. In the category of public lecture, where the data indicate that the lecture is moderately appropriate and effective, with a score of $56 \%$, it can be observed that the instructional method is inapplicable $(100 \%)$ to an individual learner. Furthermore, it has become apparent that the degree to which the lecture performs is a function of 
the content to be delivered. For instance, in a topic such as "Microbial Transformations and Fermentation", the lecture performs moderately appropriate and effective $(60 \%)$ when delivered to a small or large group. This is because in delivering a lecture on a subject matter of this like, demonstration, slide-shows, etc, are bound to be used to supplement the pure lecture. Whereas in a topic like "Nature Capitalism, State and Class Formation in Nigeria", the lecture is undoubtedly very appropriate and effective $(20 \%)$, with either small or large group.

\section{Generalizations and their Implications}

Perhaps on the basis of the discussion of the few cases in this schema, one can venture to propose some generalizations as terra firma for researchable hypotheses. The following are some of them:

1. The performance of the lecture in adult education can be said to be less effective and less appropriate whether in individual, small or large group situations; albeit expedient in large group situation, since it can cover wider grounds and large audience in the shortest possible time.

2. The lecture may in certain circumstances yield the desired results, i.e. changes in cognition and attitude, when applied in continuing education setting.

3. The lecture is least suitable in vocationally oriented and experientiallybased adult education situations.

Thus the nature, and needs of the adult learner calls for a reappraisal of the instructional methods in adult education. It is axiomatic that the lecture is synonymous with pedagogy, which invariably is an antithesis of andragogy. For adult education in. Nigeria to serve its intended purposes, training agencies will have to train the trainers in group learning process, and in so doing deemphasize the exclusive use of the much abused lecture method. However, other instructional technique and devices, viz, simulation, critical-incident process, laboratory method, consultative supervision, demonstration, case study, role-playing, field projects, group discussion, to mention just a few, should be used in conjunction with the lecture as to increase its effectiveness in adult learning. 


\section{Conclusion}

This article had two modest aims: first, to discuss the structure of adult education and attempt, rather conjuncturally, to propose relationships between it and the lecture. Second, to draw some generalizations as bases for research in adult teaching-learning processes.

At the level of praxis, adult educators are constantly discovering the instructural effectiveness and realism which group method can bring to the learning situation. There is no doubt that the lecture at one point in the time in the structural process, is invaluable in a variety of adult education setting. However, its exclusive use should be discouraged, since it fails to acknowledge the experiences which adults bring to the classroom.

At the level of theory, three generalizations are proposed, and a call is made to transform these generalizations into researchable hypotheses, so as to validate the appropriateness-effective thesis of the lecture method in adult education as advanced in this article.

\section{BIBLIOGRAPHY}

1. Ampene, E. K. (1979), "Teaching Adults: Style, Methods, and Teachnique", in Bown, L., et. al: A Handbook of Adult Education for West Africa, Hutchinson University for Africa, London.

2. Axford, L.D. (1970), "Curriculum and Content" in Smith, R.M., et al; Handbook of Adult Education, Macmillan, New York.

3. Boyle, P.G. and Jahns, I.R. (1970), Programme Development and Evaluation, Macmillan, New York.

4. Darkenwald, C.G., and Merriam, S.F. (1982), Adult Education; Foundation of Practice, Harper and Row, New York.

5. Federal Ministry of Education, J.C.C. Reference Committee on Adult and Non-Formal Education Minutes of Meetings held in Jos, April, 1982, p. 5.

6. Knowles, N.J. (1970), The Modern Practice of Adult Education, Asssociation Press, New York.

7. Knюx, A.B., et. al, (1980) Developing, Administering and Evaluating Adult Education, Jossey Bass Publishers, San Fransisco.

8. London, J.W. et. al, (1960) Programme Development in Adult Education, Adult Education Association Washington D.C.

9. Oddi, L. (1983) "The lecture: An Update on Research"; Adult Education Quarterly, Vol. 33, No. 4, Summar, 1983.

10. Tahir, G. (1982) "A Design of Adult Education for Social Action, Education Complex Seminar, A.B.U., Zaria.

11. Thomas, J.A. et. al. (1964), Adult Education and Continuing Education, Midwest Administration Centre, Chicago. 


\section{Appendix I}

Diagrammatic Presentation of the Performance of the Lecture method in selected categories of Adult Education Programs.

$\begin{array}{ccc}\begin{array}{c}\text { Adult, Education } \\ \text { Activity-Program }\end{array} & \begin{array}{c}\text { Class of } \\ \text { Participants }\end{array} & \begin{array}{c}\text { Score of appropriateness } \\ \text { effectiveness of the Lecture. }\end{array} \\ \text { (A-P) } & \text { (CP) } & \text { (AEs) }\end{array}$

1. Basic Literacy

a) Reading
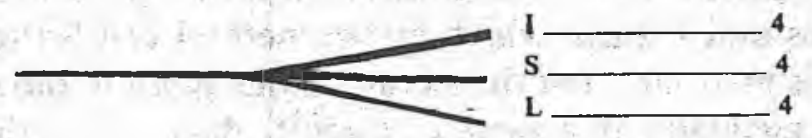

b) Writing
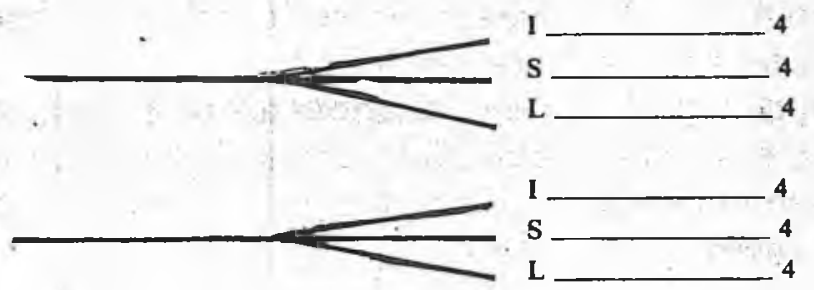

\section{Functional Literacy}

a) Reading
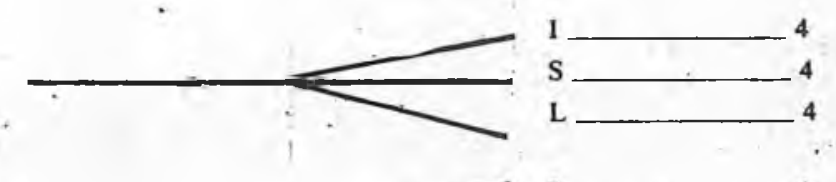

b) Writing
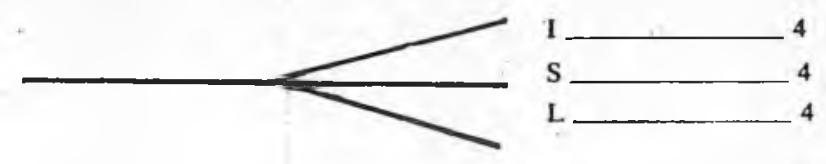

a) Arithmetic
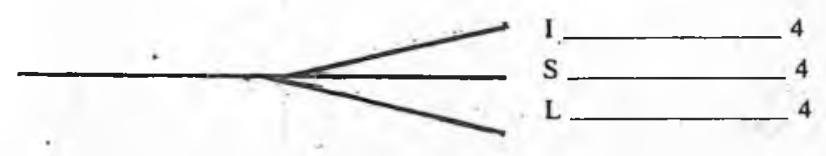

\section{Vocational Training}

a) Typewriting

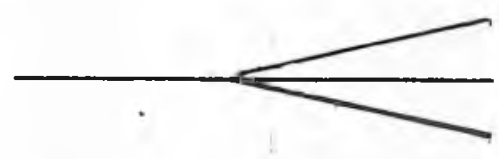

b) Mechanics

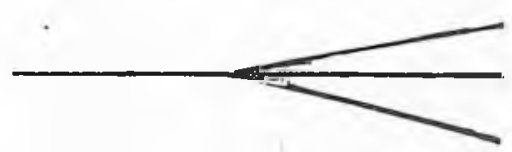

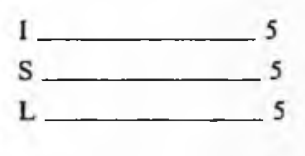

$1 \longrightarrow 5$

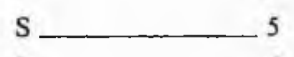


c) Sewing

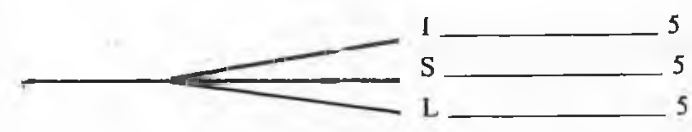

4.Community Development

a) Public Enlightenment

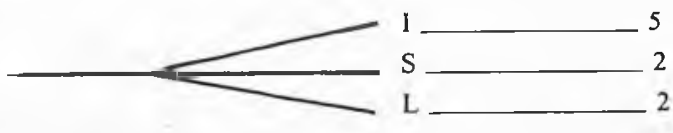

b) Feeder Road Construction

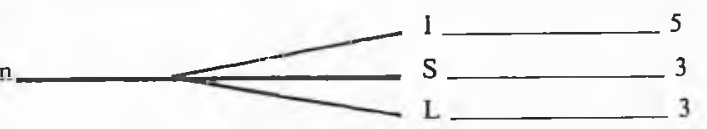

c) University Endowment Funding Raising.

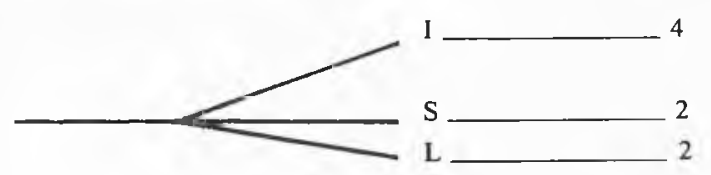

5. Correspondece Study

a) O-Level Physics

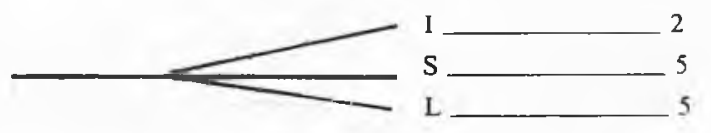

b) A-Level Literature

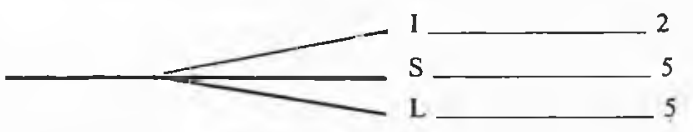

a) Open University:

Public Finance

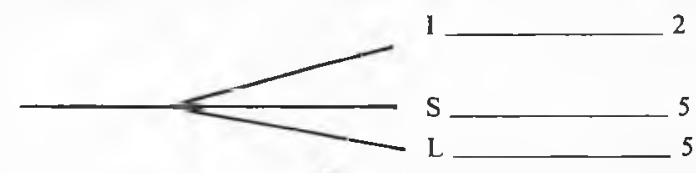

6. Extra-Mural Study

a) O-Level Maths

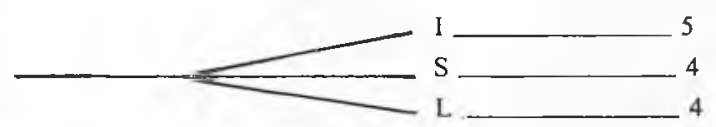

b) A-Level Zoology

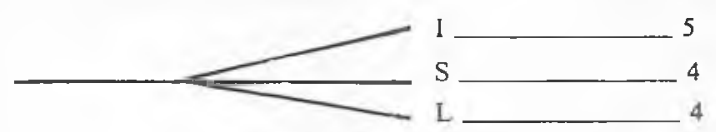

c) Open University:

Islamic Legal Theory

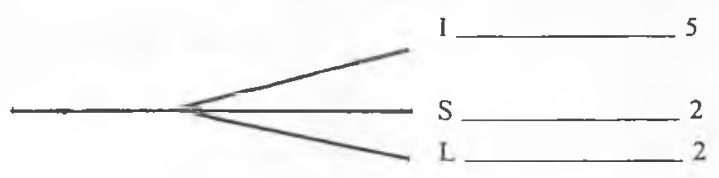




\section{Seminar and Conference}

a) Commuittee of V.Cs:

,Financing Education

b) Marx Centenary
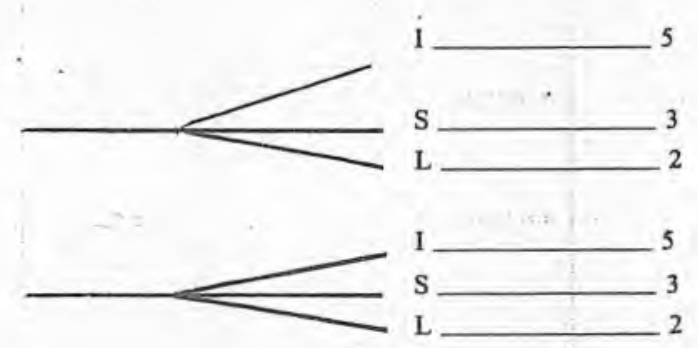

c) Adult Education

in the 1980 s

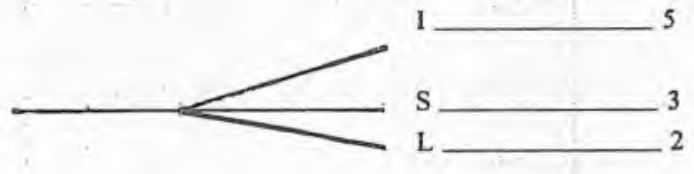

8. Workshop and Institute

a) Leadership

Training

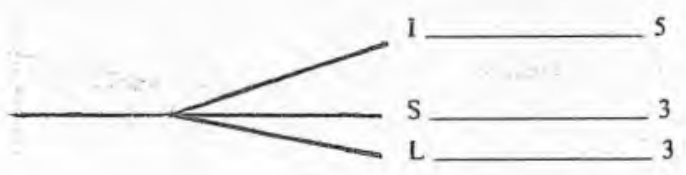

b) Evaluation of Primary Science materials

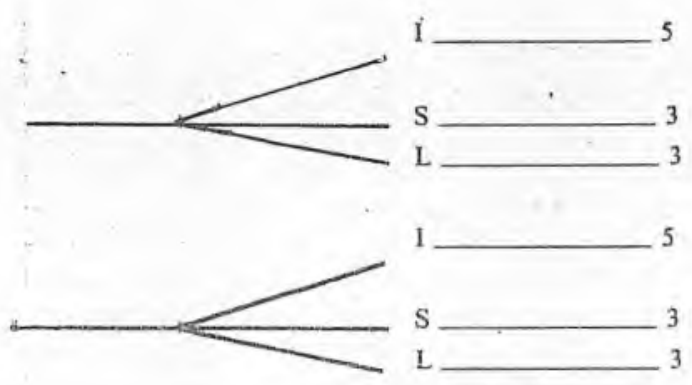

c) Activity-Teaching

Methods in Adult Education

ducatio

\section{Public Lecture}

a) Action Research in Education

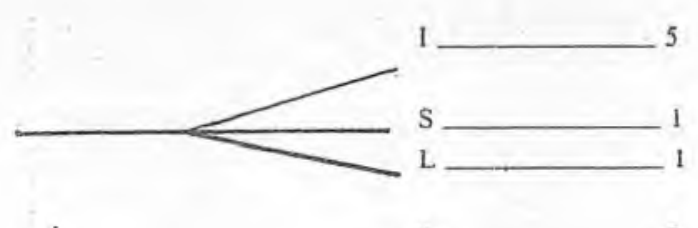

b) Microbial Transformation and Fermentation

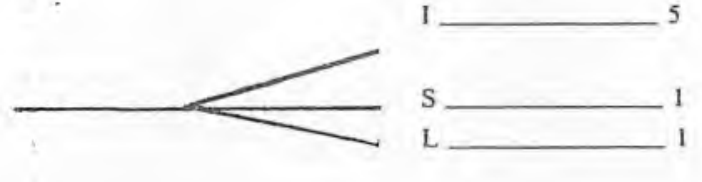




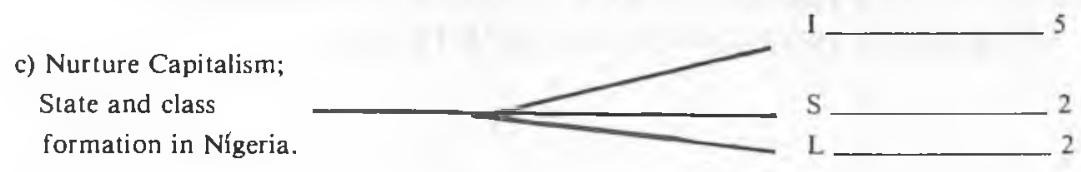

Note:

Column 1: Adult Education Activity-Programme (A-P) consists of various programs in adult education.

Column 2: Class of Participants (CP) includes individual (I), and Small (S) and Large (L) groups.

Column 3: Score of appropriateness and effectiveness of the lecture in selected adult education programmes in a give। instructional situation. The scores range between 1 to 5 on a scale. 1 stands for Very appropriate and effectivc?, for appropriate and effective, 3 for moderately appropriate and effective, 4 for not appropriate and ellut and finally 5 for not applicable. 